\title{
PENGARUH INOVASI , E-COMMERCE DAN GENDER TERHADAP MINAT BERWIRAUSAHA MAHASISWA UNIVERSITAS TARUMANAGARA
}

\author{
Ingrid Maisan dan Kartika Nuringsih \\ Program Studi Manajemen Fakultas Ekonomi Universitas Tarumanagara, Jakarta \\ ingridmaisann@gmail.com; kartikanuringsih72@gmail.com
}

\begin{abstract}
In developed countries, there will be more and more people who are highly educated or educated, and vice versa, there will be more and more people who do not have jobs or are unemployed. The purpose of this study was to determine the effect of innovation, E-commerce, and gender on the entrepreneurial interest of Tarumanagara University students. The data collection method used a questionnaire distributed to 101 respondents. The data analysis method used in this study is SEM-PLS analysis using the SmartPLS application. The results of this study indicate that innovation has a positive and significant effect on interest in entrepreneurship, E-commerce has a positive and significant influence on interest in entrepreneurship, and gender does not have a positive and significant influence on interest in entrepreneurship. This causes innovation and E-commerce variables to become important keys in controlling the variable interest in entrepreneurship of Tarumanagara University students.
\end{abstract}

Keywords: Brand Image, Brand Trust, E-purchase decision

Abstrak: Di negara yang maju, akan makin banyak orang yang berpendidikan tinggi atau terdidik, dan sebaliknya akan makin banyak juga orang yang tidak memliki pekerjaan atau pengangguran. Tujuan dari penelitian ini adalah untuk mengetahui pengaruh inovasi, Ecommerce, dan gender terhadap minat berwirausaha mahasiswa Universitas Tarumanagara. Metode pengumpulan data menggunakan kuesioner yang disebarkan kepada 101 responden. Metode analisis data yang digunakan dalam penelitian ini adalah analisis SEM-PLS menggunakan aplikasi SmartPLS. Hasil penelitian ini, menunjukan bahwa inovasi memiliki pengaruh positif dan signifikan terhadap minat berwirausaha, E-commerce memiliki pengaruh positif dan signifikan terhadap minat berwirausaha, dan gender tidak memiliki pengaruh positif dan signifikan terhadap minat berwirausaha. Hal ini menyebabkan variabel inovasi dan E-commerce menjadi kunci penting dalam upaya kontrol pada variabel minat berwirausaha mahasiswa Universitas Tarumanagara.

Kata Kunci: Brand Image, Brand Trust, E-purchase decision 


\section{LATAR BELAKANG}

Di negara yang maju, akan makin banyak orang yang berpendidikan tinggi atau terdidik, dan sebaliknya akan makin banyak juga orang yang tidak memliki pekerjaan atau pengangguran. Hal tersebut dapat dilihat dari sumber data penduduk bekerja di Indonesia yang dirilis oleh badan pusat statistik Tahun 2020 dibawah ini:

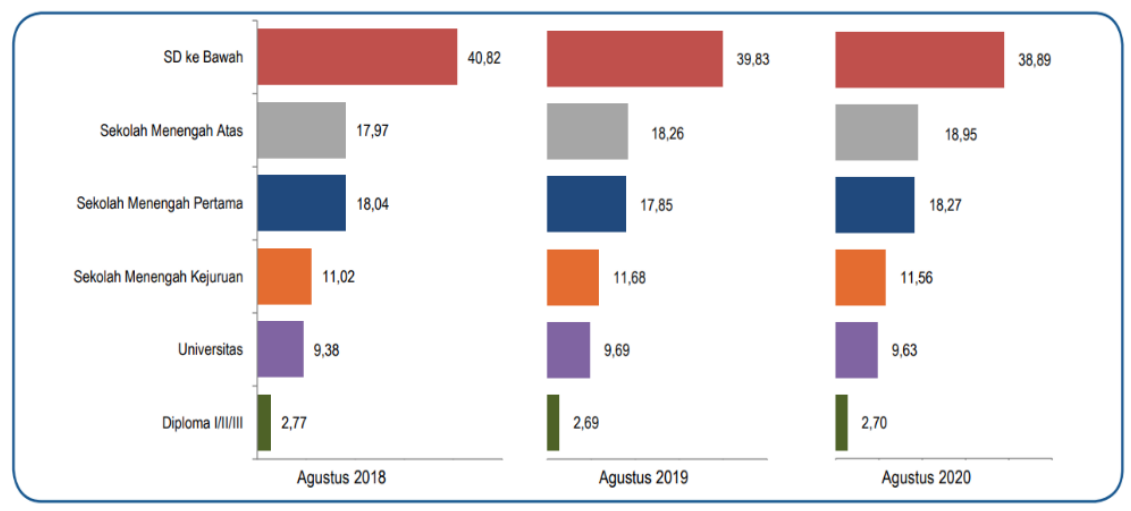

\section{Gambar 1 Persentase Penduduk Bekerja Periode Agustus 2018-Agustus 2020}

Tingkat pendidikan dapat mengindikasikan kualitas dan produktivitas tenaga kerja. Pada Agustus 2020, penduduk bekerja masih didominasi oleh mereka yang berpendidikan SD ke bawah yaitu sebanyak 38,89 persen. Sementara tenaga kerja yang berpendidikan tinggi, yaitu Diploma dan Universitas hanya sebesar 12,33 persen. Dibandingkan dengan keadaan Agustus 2019, kontribusi pendidikan pada penduduk bekerja mengalami penurunan pada pendidikan SD ke bawah (0,94 persen poin), SMK (0,12 persen poin), dan Universitas $(0,06$ persen poin). Sementara penduduk bekerja dengan peningkatan terbesar pada pendidikan SMA sebesar 0,69 persen poin (Badan Pusat Statistik Indonesia, 2020).

Pembinaan jiwa kewirausahaan para mahasiswa diyakini menjadi salah satu cara dan solusi untuk mengurangi tingkat pengangguran. Solusi semacam ini telah dilakukan dan ditangani secara luas di negara-negara maju (Kaijun \& Ichwatus Sholihah, 2015). Mahasiswa yang memiliki jiwa kewirausahaan akan menjadikan mahasiswa tersebut memiliki kemandirian ekonomi sehingga kedepannya mahasiswa tersebut dapat diharapkan menciptakan lapangan kerja guna bersaing dalam era globalisasi saat ini serta mengurangi tingkat pengangguran yang ada di Indonesia.

Proses globalisasi yang sedang terjadi tersebut menuntut perubahan perekonomian suatu negara dari resource based menuju knowledge base. Resource base mengandalkan kekayaan dan keragaman sumber daya alam umumnya menghasilkan komoditi dasar dengan nilai tambah yang kecil. Sedangkan knowledge base bisa diciptakan dengan adanya technopreneur yang merintis usaha atau bisnis baru dengan mengandalkan inovasi. Ini salah satu yang menjadi alasan mengapa technopreneur sangat dibutuhkan di era globalisasi saat ini (Siregar et al., 2020).

Menzies dan Tatroff (2006) mengeksplorasi sikap siswa di Kanada. Mereka mengidentifikasi tidak ada perbedaan dalam sikap mengambil risiko, tetapi lebih sedikit wanita cenderung berpikir bahwa kewirausahaan sesuai kepribadian mereka. Daim et al. (2015) mereka juga melaporkan studi yang mengutip bagaimana pendidikan membantu meningkatkan jumlah pengusaha perempuan. Verheul et al. (2006) mengeksplorasi serupa 
faktor-faktor di universitas AS dan menemukan hasil yang sama. Kourilsky dan Walstad (1998) juga mengidentifikasi perbedaan serupa dalam studi di seluruh AS dan mengusulkan Kurikulum.

Zhang et al. (2009) mengeksplorasi perbedaan genetik antara jenis kelamin dan dampaknya terhadap kewirausahaan. Petridou et al. (2009) mengidentifikasi bahwa ada perbedaan sikap terhadap pendidikan kewirausahaan dan persepsi tentang keterampilan yang diperlukan antara kedua jenis kelamin. Eddleston dan Powell (2008) diperiksa bagaimana identitas gender menjelaskan dari mana pemilik bisnis pria dan wanita karir mereka dan menemukan bahwa identitas gender, diwakili oleh dimensi maskulinitas dan feminitas, berfungsi sebagai mekanisme kognitif yang berkontribusi pada perbedaan preferensi kepuasan karier pemilik bisnis. Verheul et al. (2006) mengeksplorasi kewirausahaan perempuan di 29 negara dan menemukan bahwa faktor serupa berdampak pada kedua jenis kelamin. Grilo dan Thurik (2004) juga mengidentifikasi perbedaan gender dalam sebuah penelitian yang dilakukan pada populasi umum. Gerry et al. (2008) mengidentifikasi perbedaan serupa di Portugal. Keduanya sedang mengeksplorasi kewirausahaan sebagai Pilihan. Namun, Fischer et al. (1993) berdebat menentang perbedaan ini dan menemukan bahwa tidak ada perbedaan dalam tingkat keberhasilan pada akhirnya.

\section{KAJIAN TEORI}

\section{Inovasi}

Inovasi adalah proses multi-tahap di mana organisasi mengubah ide menjadi produk, layanan, atau proses baru / lebih baik, untuk memajukan, bersaing, dan berhasil membedakan diri mereka di pasar (Baregheh et al., 2009).

Zahra dan Covin (1994) menunjukkan bahwa "Inovasi secara luas dianggap sebagai darah kehidupan kelangsungan hidup dan pertumbuhan perusahaan". Inovasi diakui memainkan peran sentral dalam menciptakan nilai dan mempertahankan keunggulan kompetitif. Bessant et al. (2005) pada peran inovasi dalam pembaruan dan penekanan pertumbuhan "Inovasi mewakili proses perpanjangan inti di organisasi apa pun. Kecuali itu mengubah apa yang ditawarkannya kepada dunia dan cara di mana ia menciptakan dan memberikan penawaran tersebut berisiko kelangsungan hidup dan prospek pertumbuhan". Signifikansi inovasi tidak terbatas pada organisasi bisnis. AS memiliki Departemen Inovasi (2008), dan di Inggris telah tersebar luas dan pengakuan berkelanjutan tentang pentingnya inovasi. Kewirausahaan adalah proses mengidentifikasi, mengembangkan, dan membawa visi ke dalam kehidupan. Visi tersebut bisa berupa ide inovatif, peluang, cara yang lebih baik dalam menjalankan sesuatu (Jo \& Puspitowati, 2019).

\section{E-Commerce}

Menurut Turban et al. (2017) Perdagangan elektronik (electronic commerce, disingkat $\mathrm{EC}$, atau e-commerce) mencangkup proses pembelian, penjualan, transfer, atau pertukaran produk, layanan atau informasi melalui jaringan komputer, termasuk internet. Beberapa orang memandang istilah perdagangan (e-commerce) hanya untuk menjelaskan transaksi yang dapat dilakukan antar mitra bisnis. Jika definisi ini digunakan, beberapa orang menyadari bahwa istilah e-commerce sangat sempit. Sehingga, banyak yang menggunakan istilah e-bussines sebagai istilah penggantinya. Bisnis elektronik (electronic bussines atau e-bussines) mengarah pada definisi EC yang lebih luas, tidak adanya pembelian dan penjualan barang saja. Tetapi juga layanan pelanggan, kolaborasi dengan mitra bisnis. Lainnya memandang ebussines sebagai "aktivitas selain pembelian dan penjualan" di internet, seperti kolaborasi dan aktivitas intra bisnis 


\section{Gender}

Pengertian gender menurut Muhtar (2002) bahwa gender dapat diartikan sebagai jenis kelamin sosial atau konotasi masyarakat untuk menentukan peran sosial berdasarkan jenis kelamin. Sementara Fakih (2005) menyatakan gender sebagai suatu sifat yang melekat pada kaum laki-laki maupun perempuan yang dikonstruksi secara sosial dan kultural. Istilah gender dibedakan dari istilah seks Oakley 1997 ahli Sosiologi Inggris, merupakan orang yang mula-mula memberikan pembedaan dua istilah itu Saptari dan Holzner (1997). Istilah gender merujuk kepada perbedaan karakter laki-laki dan perempuan berdasarkan kontruksi sosial budaya, yang berkaitan dengan sifat, status, posisi, dan perannya dalam masyarakat. Istilah Seks merujuk kepada perbedaan jenis kelamin laki-laki dan perempuan secara biologis terutama yang berkaitan dengan prokreasi dan reproduksi. Laki-laki dicirikan dengan adanya sperma dan penis serta perempuan dicirikan dengan adanya sel telur, rahim, vagina, dan payudara. Ciri jenis kelamin secara biologis tersebut bersifat bawaan, permanen, dan tidak dapat dipertukarkan (Abdullah, 2004).

4. Minat Berwirausaha

Menurut Slameto (2010) minat adalah suatu rasa lebih suka dan rasa keterikatan pada suatu hal atau aktivitas, tanpa ada yang menyuruh. Minat pada dasarnya adalah penerimaan akan suatu hubungan antara diri sendiri dengan sesuatu di luar diri. Minat berwirausaha akan menjadikan seseorang lebih giat mencari dan memanfaatkan peluang usaha dengan mengoptimalkan potensi yang dimiliki. Minat berwirausaha merupakan keinginan, ketertarikan, serta kesediaan individu untuk bekerja keras dalam memenuhi kebutuhan hidupnya tanpa takut dengan resiko yang akan terjadi (Anggraeni \& Harnanik, 2015). Minat berperan sangat penting dalam kehidupan peserta didik dan mempunyai dampak yang besar terhadap sikap dan perilaku. Pendidikan kewirausahaan terdiri dari program (pedagogi) atau proses pendidikan apa pun untuk sikap dan keterampilan wirausaha (Marchel \& Nuringsih, 2020). Mahasiswa yang memiliki minat terhadap sesuatu cenderung mempunyai ketertarikan untuk mengetahui dan mempelajari hal-hal yang berkaitan dengan minat tanpa adanya paksaan. Seseorang dikatakan memiliki minat berwirausaha yang tinggi dapat dilihat dari berbagai aspek kepribadian seperti watak, sikap dan perilaku seseorang.

\section{METODOLOGI}

Menguraikan dengan singkat mengenai: subyek dan obyek riset, operasionalisasi variabel, populasi dan sampel apa, metode sampling, dan uji statistik yang digunakan pada riset saudara.Obyek dan subyek riset ini adalah Mahasiswa Universitas Tarumanagara. Metode pengambilan sampel dengan purposive sampling, dengan kriteria Mahasiswa Universitas Tarumanagara yang mengikuti Mata Kuliah Kewirausahaan. Adapun untuk operasionalisasi variabel pada riset ini dapat dijelaskan oleh Tabel 1 dibawah ini:

Tabel 1

Variabel Operasional

\begin{tabular}{llll}
\hline Variabel & Definisi & Indikator & \multicolumn{2}{l}{ Jenis Data } \\
\hline Inovasi & Inovasi adalah proses & 1. Kekuatan & Ordinal \\
& multi-tahap di mana & 2. Keunikan & Likert) \\
& $\begin{array}{l}\text { organisasi mengubah ide } \\
\text { menjadi produk, layanan, }\end{array}$ & 3. Keunggulan & \\
& & \\
\hline
\end{tabular}




\begin{tabular}{|c|c|c|c|}
\hline Variabel & Definisi & Indikator & Jenis Data \\
\hline & $\begin{array}{l}\text { atau proses baru / lebih } \\
\text { baik, untuk memajukan, } \\
\text { bersaing, dan berhasil } \\
\text { membedakan diri mereka di } \\
\text { pasar (Baregheh et al., } \\
\text { 2009) }\end{array}$ & & \\
\hline E-Commerce & $\begin{array}{l}\text { Menurut Turban et al. } \\
\text { (2017) Perdagangan } \\
\text { elektronik (electronic } \\
\text { commerce, disingkat EC, } \\
\text { atau e-commerce) } \\
\text { mencangkup proses } \\
\text { pembelian, penjualan, } \\
\text { transfer, atau pertukaran } \\
\text { produk, layanan atau } \\
\text { informasi melalui jaringan } \\
\text { komputer, termasuk } \\
\text { internet }\end{array}$ & $\begin{array}{l}\text { 1. Mudah diakses } \\
\text { 2. Transasksi mudah } \\
\text { dilakukan } \\
\text { 3. Permodalan } \\
\text { 4. Transaksi aman } \\
\text { 5. Proses pelayanan cepat }\end{array}$ & $\begin{array}{l}\text { Ordinal } \\
\text { Likert) }\end{array}$ \\
\hline Gender & $\begin{array}{l}\text { Pengertian gender menurut } \\
\text { Muhtar (2002), bahwa } \\
\text { gender dapat diartikan } \\
\text { sebagai jenis kelamin sosial } \\
\text { atau konotasi masyarakat } \\
\text { untuk menentukan peran } \\
\text { sosial berdasarkan jenis } \\
\text { kelamin }\end{array}$ & $\begin{array}{l}\text { 1. Laki - Laki } \\
\text { 2. Perempuan } \\
\end{array}$ & Nominal \\
\hline $\begin{array}{l}\text { Minat } \\
\text { Berwirausaha }\end{array}$ & $\begin{array}{l}\text { Minat berwirausaha } \\
\text { merupakan keinginan, } \\
\text { ketertarikan, serta } \\
\text { kesediaan individu untuk } \\
\text { bekerja keras dalam } \\
\text { memenuhi kebutuhan } \\
\text { hidupnya tanpa takut } \\
\text { dengan resiko yang akan } \\
\text { terjadi (Anggraeni \& } \\
\text { Harnanik, 2015). }\end{array}$ & $\begin{array}{l}\text { 1. Ambition for freedom } \\
\text { 2. Self-realisation } \\
\text { 3. Pushing factors }\end{array}$ & $\begin{array}{l}\text { Ordinal (Skala } \\
\text { Likert) }\end{array}$ \\
\hline
\end{tabular}

Sumber: Baregheh et al. (2009); Turban et al. (2017); Muhtar (2002); Anggraeni dan Harnanik (2015)

Pemodelan persamaan struktural (SEM) adalah teknik multivariat yang memungkinkan estimasi simultan dari beberapa persamaan yang terdiri dari analisis faktor, analisis regresi ganda, dan analisis model jalur (Hasman, 2015; Singh \& Sharma, 2016). Model Persamaan Struktural terdiri dari dua model: model variabel laten dan model pengukuran (Hair et al., 2014; Tenenhaus, 2008). Ada dua yang berbeda dalam model pengukuran, peneliti mengukur variabel laten (Usakli \& Kucukergin, 2018). Berdasarkan analisis jalur, peneliti memeriksa semua ketergantungan hipotetis dalam model struktural (Cepeda-Carrion et al., 2019). Untuk menganalisis model 
menggunakan Pemodelan Persamaan Struktural, peneliti menggunakan SmartPLS 3 sebagai aplikasi analisis (Hair et al., 2014; Hair et al., 2018).

\section{Hasil Analisis Data}

1. Outer Model

Tabel 2

Convergent Validity

\begin{tabular}{|c|c|c|c|c|}
\hline Variabel Latent & Contruct/Item & $\begin{array}{l}\text { Item } \\
\text { loading }\end{array}$ & AVE & Hasil \\
\hline \multirow[t]{6}{*}{ Inovasi (IO) } & & & 0.532 & Reliable \\
\hline & IO1 & 0.688 & & Valid \\
\hline & $\mathrm{IO} 2$ & 0.817 & & Valid \\
\hline & IO3 & 0.766 & & Valid \\
\hline & $\mathrm{IO} 4$ & 0.576 & & Valid \\
\hline & IO5 & 0.774 & & Valid \\
\hline \multirow{6}{*}{$\begin{array}{l}\text { E-Commerce } \\
\text { (EC) }\end{array}$} & & & 0.579 & Reliable \\
\hline & EC1 & 0.635 & & Valid \\
\hline & EC2 & 0.826 & & Valid \\
\hline & EC3 & 0.825 & & Valid \\
\hline & EC4 & 0.804 & & Valid \\
\hline & EC5 & 0.695 & & Valid \\
\hline \multirow{2}{*}{$\begin{array}{l}\text { Gender } \\
\text { (GE) }\end{array}$} & & & 1.000 & Reliable \\
\hline & GE1 & 1.000 & & Valid \\
\hline \multirow{6}{*}{$\begin{array}{l}\text { Minat Berwirausaha } \\
\text { (MB) }\end{array}$} & & & 0.501 & Reliable \\
\hline & MB1 & 0.757 & & Valid \\
\hline & MB2 & 0.789 & & Valid \\
\hline & MB3 & 0.622 & & Valid \\
\hline & MB4 & 0.694 & & Valid \\
\hline & MB5 & 0.665 & & Valid \\
\hline
\end{tabular}

Sumber: Data primer diproses di SmartPLS

Tabel 3

HTMT Ratio

\begin{tabular}{|l|l|l|l|l|}
\hline & IO & EC & GE & MB \\
\hline IO & & & & \\
\hline EC & 0,754 & & & \\
\hline GE & 0.087 & 0.303 & & \\
\hline MB & 0.838 & 0.682 & 0.091 & \\
\hline
\end{tabular}

Sumber: Data primer diproses di SmartPLS 
Tabel 4

Construct Reliability

\begin{tabular}{|l|r|r|}
\hline & Cronbach's Alpha & Composite Reliability \\
\hline Inovasi & $\mathbf{0 . 7 7 6}$ & $\mathbf{0 . 8 4 9}$ \\
\hline E-Commerce & $\mathbf{0 . 8 1 9}$ & $\mathbf{0 . 8 7 2}$ \\
\hline Gender & 1.000 & $\mathbf{1 . 0 0 0}$ \\
\hline Minat Berwirausaha & $\mathbf{0 . 7 5 2}$ & $\mathbf{0 . 8 3 3}$ \\
\hline
\end{tabular}

Sumber: Data primer diproses di SmartPLS

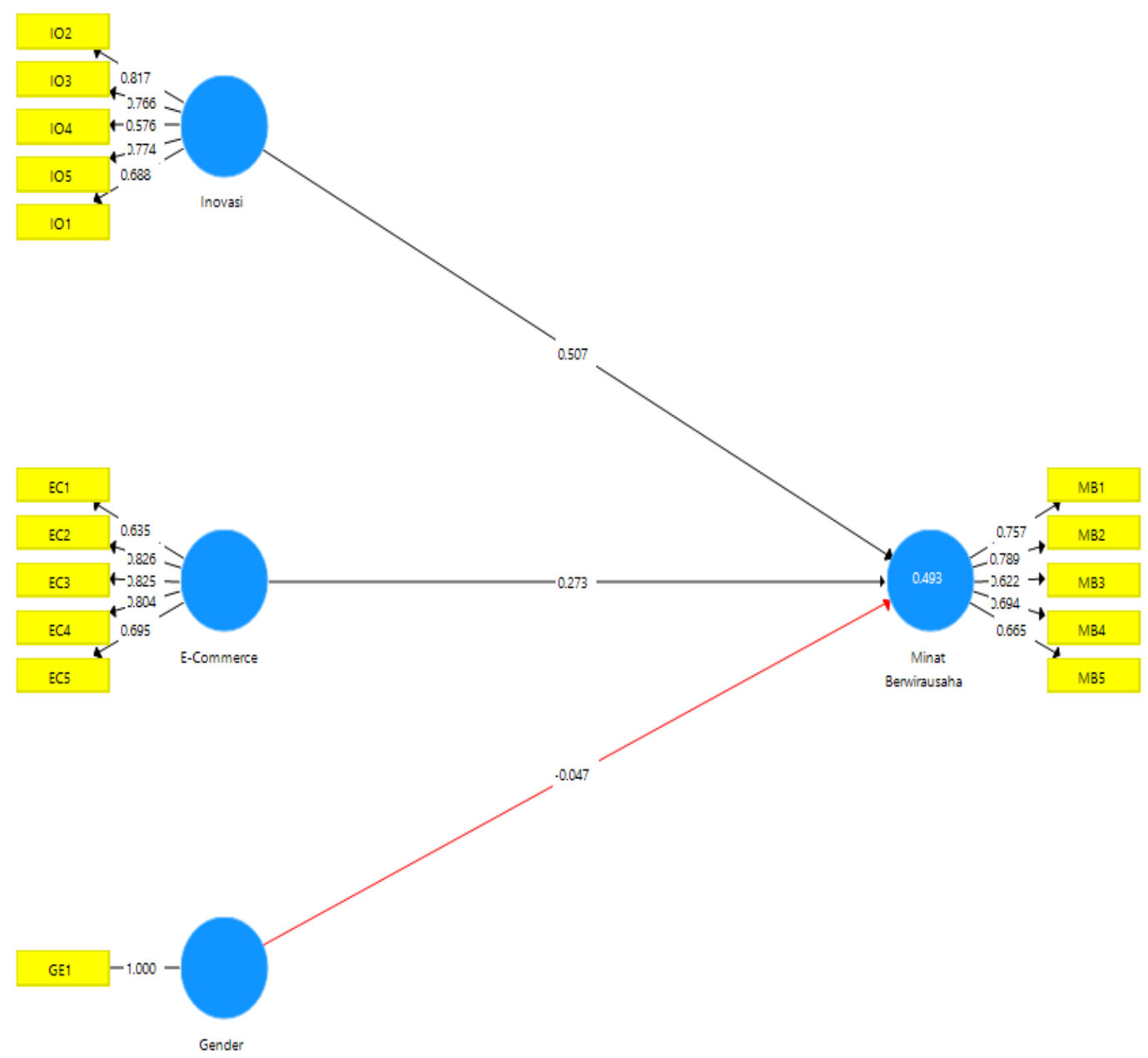

Gambar 2 Hasil Outer Model 
Tabel 5

Hasil Uji DIrect Effect

\begin{tabular}{|l|l|l|l|l|l|}
\hline & & Estimate & $\begin{array}{l}\text { T } \\
\text { Statistics }\end{array}$ & P Values & Hasil \\
\hline H1 & Inovasi -> Minat Berwirausaha & 0.507 & 5.570 & $\mathbf{0 . 0 0 0}$ & Significant \\
\hline H2 & $\begin{array}{l}\text { E-Commerce -> Minat } \\
\text { Berwirausaha }\end{array}$ & 0.273 & 2.673 & $\mathbf{0 . 0 0 8}$ & Significant \\
\hline H3 & \begin{tabular}{l} 
Gender-> Minat Berwirausaha \\
\hline
\end{tabular} & -0.047 & 0.611 & $\mathbf{0 . 5 4 1}$ & $\begin{array}{l}\text { Not } \\
\text { Significant }\end{array}$ \\
\hline
\end{tabular}

Sumber: Data primer diproses di SmartPLS

Tabel 6

Hasil Koefisien Determinasi

\begin{tabular}{|l|c|c|}
\hline & R Square Adjusted & Hasil \\
\hline IO \& EC-MB & 0.477 & Sedang \\
\hline
\end{tabular}

Diskusi

1. Pengaruh Inovasi Terhadap Minat Berwirausaha

Seperti yang ditampilkan dalam Tabel 5, hubungan antara Inovasi dan Minat Berwirausaha memiliki nilai $\mathrm{T}$ statistik 5.570, yang lebih besar dari 1.96 dan nilai PValue 0.000 lebih kecil dari 0.05 (5\%). Hasilnya berarti memenuhi kriteria hubungan yang signifikan, yang membuat Ho1 ditolak dan Ha1 diterima. Oleh karena itu, dapat disimpulkan bahwa Inovasi secara signifikan mempengaruhi Minat Berwirausaha.

Temuan ini mirip dengan temuan dari Sektiyaningsih dan Aisyah (2020) yang menyatakan bahwa Inovasi berpengaruh signifikan dan positif terhadap Minat Berwirausaha. Secara khusus, inovasi pada penelitian ini menjadikan dampak yang posif bagi mahasiswa untuk dapat memacu minat berwirausaha dikarenakan banyaknya ide yang ditimbulkan dari peran inovasi sehingga dapat bersaing di dunia usaha dengan kreatifitas dari inovasi itu sendiri.

2. Pengaruh E-Commerce Terhadap Minat Berwirausaha

Seperti yang ditampilkan dalam Tabel 5, hubungan antara E-Commerce dan Minat Berwirausaha memiliki nilai T statistik 2.673, yang lebih besar dari 1.96 dan nilai PValue 0.008 lebih kecil dari 0.05 (5\%). Hasilnya berarti memenuhi kriteria hubungan yang signifikan, yang membuat $\mathrm{Ho} 2$ ditolak dan $\mathrm{Ha} 2$ diterima. Oleh karena itu, dapat disimpulkan bahwa E-Commerce secara signifikan mempengaruhi Minat Berwirausaha. Temuan ini mirip dengan temuan dari Yadewani dan Wijaya (2017) dimana dinyatakan bahwa E-Commerce berpengaruh signifikan dan positif terhadap Minat Berwirausaha. Secara khusus, E-Commerce pada penelitian ini dapat menjadi alat pendukung dalam proses bisnis di era digital padda saat ini, dimana banyak nya wirausaha millenial yang menggunakan E-Commerce sebagai media untuk berwirausaha dengan mudah dan praktis.

3. Pengaruh GenderTerhadap Minat Berwirausaha

Seperti yang ditampilkan dalam Tabel 5, hubungan antara Gender dan Minat Berwirausaha memiliki nilai $\mathrm{T}$ statistik 0.611 , yang lebih kecil dari 1.96 dan nilai PValue 0.541 lebih besar dari 0.05 (5\%). Hasilnya berarti tidak memenuhi kriteria 
hubungan yang signifikan, yang membuat Ho3 diterima dan Ha3 ditolak. Oleh karena itu, dapat disimpulkan bahwa Gender tidak berpengaruh terhadap Minat Berwirausaha.

Temuan ini mirip dengan temuan dari Damayanti (2013) dimana dinyatakan bahwa Gender tidak berpengaruh pada Minat Berwirausaha. Secara khusus, Gender pada penelitian ini mendapatkan hasil yang tidak signifikan dikarenakan Minat Berwirausaha pada Gender dipengaruhi berbagai macam faktor baik internal maupun eksternal.

\section{KESIMPULAN}

Terdapat beberapa kesimpulan dari hasil penelitian ini yaitu sebagai berikut:

1. Inovasi berpengaruh positif terhadap Minat Berwirausaha. Inovasi pada penelitian ini menjadikan dampak yang posif bagi mahasiswa untuk dapat memacu minat berwirausaha dikarenakan banyaknya ide yang ditimbulkan dari peran inovasi sehingga dapat bersaing di dunia usaha dengan kreatifitas dari inovasi itu sendiri.

2. E-Commerce berpengaruh positif terhadap Minat Berwirausaha. E-Commerce pada penelitian ini dapat menjadi alat pendukung dalam proses bisnis di era digital padda saat ini, dimana banyak nya wirausaha millenial yang menggunakan E-Commerce sebagai media untuk berwirausaha dengan mudah dan praktis.

3. Gender tidak berpengaruh positif terhadap Minat Berwirausaha. Secara khusus, Gender pada penelitian ini mendapatkan hasil yang tidak signifikan dikarenakan Minat Berwirausaha pada Gender dipengaruhi berbagai macam faktor baik internal maupun eksternal.

\section{DAFTAR PUSTAKA}

Abdullah, A. (2004). Kesetaraan Gender di Perguruan Tinggi Islam. In McGill-IAINIndonesia Social Equity Project. McGill-IAIN-Indonesia Social Equity Project.

Anggraeni, B., \& Harnanik, H. (2015). Pengaruh pengetahuan kewirausahaan dan lingkungan keluarga terhadap minat berwirausaha siswa kelas xi smk islam nusantara comal kabupaten pemalang. Dinamika Pendidikan, 10(1), 42-52.

Badan Pusat Statistik Indonesia. (2020). Keadaan Ketenagakerjaan Indonesia Agustus 2020.

Baregheh, A., Rowley, J., \& Sambrook, S. (2009). Towards a multidisciplinary definition of innovation. Management Decision, 47(8), 1323-1339. https://doi.org/10.1108/00251740910984578

Bessant, J., Lamming, R., Noke, H., \& Phillips, W. (2005). Managing innovation beyond the steady state. Technovation, 25(12), 1366-1376.

Cepeda-Carrion, G., Cegarra-Navarro, J. G., \& Cillo, V. (2019). Tips to use partial least squares structural equation modelling (PLS-SEM) in knowledge management. Journal of Knowledge Management, 23(1), 67-89. https://doi.org/10.1108/JKM-05-2018-0322

Daim, T., Dabic, M., \& Bayraktaroglu, E. (2015). Students' entrepreneurial behavior: international and gender differences. Journal of Innovation and Entrepreneurship, 5(1). https://doi.org/10.1186/s13731-016-0046-8

Damayanti, N. (2013). Perbedaan jenis kelamin terhadap minat berwirausaha mahasiswa jurusan pendidikan ekonomi universitas negeri surabaya. Jurnal Pendidikan Tata Niaga, 1(3), 1-16.

Eddleston, K. A., \& Powell, G. N. (2008). The role of gender identity in explaining sex differences in business owners' career satisfier preferences. Journal of Business Venturing, 23(2), 244-256. 
Fakih, M. (2005). Analisis Gender \& Transformasi Sosial. Pustaka Pelaja.

Fischer, E. M., Reuber, A. R., \& Dyke, L. S. (1993). A theoretical overview and extension of research on sex, gender, and entrepreneurship. Journal of Business Venturing, 8(2), 151-168.

Gerry, C., Marques, C. S., \& Nogueira, F. (2008). Tracking student entrepreneurial potential: Personal attributes and the propensity for business start-ups after graduation in a Portuguese university. Problems and Perspectives in Management, 6(4), 46-54.

Grilo, I., \& Thurik, R. (2004). Determinants Of Entrepreneurship In Europe E RASMUS R ESEARCH I NSTITUTE OF M ANAGEMENT REPORT SERIES.

Hair, J. F., Risher, J. J., Sarstedt, M., \& Ringle, C. M. (2018). The Results of PLS-SEM Article information. European Business Review, 31(1), 2-24. https://doi.org/10.1108/EBR-11-2018-0203

Hair, J. F., Sarstedt, M., Hopkins, L., \& Kuppelwieser, V. G. (2014). Partial least squares structural equation modeling (PLS-SEM): An emerging tool in business research. European Business Review, 26(2), 106-121. https://doi.org/10.1108/EBR-10-20130128

Hasman, A. (2015). An introduction to structural equation modeling. Studies in Health Technology and Informatics, 213, 3-6. https://doi.org/10.3233/978-1-61499-538-8-3

Jo, Y., \& Puspitowati, I. (2019). Pengaruh Educational Support Dan Relation Support Terhadap Minat Berwirausaha Mahasiswa Universitas Tarumanagara. Jurnal Manajerial Dan Kewirausahaan, I(3), 635-644. http://journal.untar.ac.id/index.php/JMDK/article/view/5376

Kaijun, Y., \& Ichwatus Sholihah, P. (2015). A comparative study of the Indonesia and Chinese educative systems concerning the dominant incentives to entrepreneurial spirit (desire for a new venturing) of business school students. Journal of Innovation and Entrepreneurship, 4(1), 1-16. https://doi.org/10.1186/s13731-014-0014-0

Kourilsky, M. L., \& Walstad, W. B. (1998). Entrepreneurship and female youth: Knowledge, attitudes, gender differences, and educational practices. Journal of Business Venturing, 13(1), 77-88.

Marchel, E., \& Nuringsih, K. (2020). Entrepreneurial Education , Green Orientation Entrepreneur, dan Green Value terhadap Ecology Entrepreneurial Intention. II(4), 914-924.

Menzies, T. V, \& Tatroff, H. (2006). The propensity of male vs. female students to take courses and degree concentrations in entrepreneurship. Journal of Small Business \& Entrepreneurship, 19(2), 203-223.

Muhtar, Y. (2002). Pendidikan Berperspektif Keadilan Gender. Depdiknas.

Petridou, E., Sarri, A., \& Kyrgidou, L. P. (2009). Entrepreneurship education in higher educational institutions: the gender dimension. Gender in Management: An International Journal.

Saptari, \& Holzner. (1997). Perempuan, Kerja, dan Perubahan Sosial: Sebuah Pengantar Studi Perempuan. Pustaka Utama Grafiti.

Sektiyaningsih, I. S., \& Aisyah, S. (2020). Analisis pengaruh pendidikan kewirausahaan, inovasi, dan motivasi berwirausaha terhadap minat berwirausaha pada mahasiswa IBM Asmi Jakarta. JMBA Jurnal Manajemen Dan ..., 06(02), 67-77.

Singh, V., \& Sharma, S. K. (2016). Analyzing the moderating effects of respondent type and experience on the fuel efficiency improvement in air transport using structural equation modeling. European Transport Research Review, 8(2). https://doi.org/10.1007/s12544016-0199-3 
Siregar, D., Purnomo, A., Mastuti, R., Napitupulu, D., Sadalia, I., Sutiksno, D. U., Putra, S. H., Sahir, S. H., Revida, E., \& Simarmata, J. (2020). Technopreneurship: Strategi dan Inovasi. Yayasan Kita Menulis.

Slameto. (2010). Belajar dan Faktor-faktor yang Mempengaruhinya. Rineka Cipta.

Tenenhaus, M. (2008). Component-based structural equation modelling. Total Quality Management and Business Excellence, 19(7-8), 871-886. https://doi.org/10.1080/14783360802159543

Turban, E., Outland, J., King, D., Lee, J. K., Liang, T.-P., \& Turban, D. C. (2017). Electronic commerce 2018: a managerial and social networks perspective. Springer.

Usakli, A., \& Kucukergin, K. G. (2018). Using partial least squares structural equation modeling in hospitality and tourism: Do researchers follow practical guidelines? In International Journal of Contemporary Hospitality Management (Vol. 30, Issue 11). https://doi.org/10.1108/IJCHM-11-2017-0753

Verheul, I., Stel, A., \& Thurik, R. (2006). Explaining female and male entrepreneurship at the country level. Entrepreneurship and Regional Development, 18(2), 151-183.

Yadewani, D., \& Wijaya, R. (2017). Jurnal Resti. Resti, 1(1), 19-25.

Zahra, S. A., \& Covin, J. G. (1994). The financial implications of fit between competitive strategy and innovation types and sources. The Journal of High Technology Management Research, 5(2), 183-211.

Zhang, Z., Zyphur, M. J., Narayanan, J., Arvey, R. D., Chaturvedi, S., Avolio, B. J., Lichtenstein, P., \& Larsson, G. (2009). The genetic basis of entrepreneurship: Effects of gender and personality. Organizational Behavior and Human Decision Processes, $110(2), 93-107$. 